\title{
Comparative effect of nadolol and propranolol on exercise tolerance in patients with angina pectoris
}

\author{
GAIL G. TURNER, RICHARD R. NELSON, LEONARD A. NORDSTROM, \\ HELMUT C. DIEFENTHAL, AND FREDARICK L. GOBEL
}

From the Cardiovascular Section, Department of Medicine and the Department of Radiology, Veterans Administration Hospital and the University of Minnesota, Minneapolis, Minnesota, USA

SUMMARY The effect of nadolol, a new long-acting beta-adrenergic blocking drug, on exercise tolerance was compared with propranolol in a randomised, double-blind crossover study involving 14 patients with angina pectoris caused by coronary artery disease. Exercise tolerance was evaluated by graded upright exercise testing to symptom-tolerated maximal exercise. Cardiac function was evaluated by sequential phonocardiograms, echocardiograms, and chest $x$-rays synchronised to end-diastole.

At the same daily dose, both drugs decreased consumption of glyceryl trinitrate to an equal extent $(P<0.02)$ but nadolol $240 \mathrm{mg}$ a day reduced episodes of angina pectoris more significantly than the same amount of propranolol $(P<0.05)$. In addition, both drugs resulted in similar improvements in exercise tolerance $(30 \%, \mathrm{P}<0.01)$, and external work performed $(48 \%, \mathrm{P}<0.01)$. A slightly greater suppression of the heart rate during exercise was observed with nadolol than with propranolol $(\mathrm{P}<0.05)$. Though both drugs caused a significant decrease in the resting heart rate, the rate corrected systolic time intervals changed very little from control. The effects of the two drugs could not be differentiated by echocardiography or phonocardiography. Cardiac end-diastolic volume measured from a chest $x$-ray film was increased during treatment with both nadolol $(15 \%, \mathrm{P}<0.01)$ and propranolol therapy $(11 \%, P<0.001)$, but a slightly greater transverse cardiac diameter $(P<0.02)$ and cardiothoracic ratio $(4 \%, P<0.001)$ was associated with nadolol.

Nadolol was as effective as propranolol in relieving symptoms and improving exercise tolerance in patients with angina pectoris. The effect of the drugs was best evaluated by the suppression of the exercising heart rate Nadolol appears to be slightly more potent than propranolol and has the advantage of a more convenient dosage schedule, but has a similar myocardial depressant effect.

Considerable evidence indicates that propranolol improves exercise tolerance in patients with angina pectoris, but has the disadvantage of having a short duration of action and of depressing both the myocardium and conduction tissue (Frankl et al., 1974; Alderman et al., 1975; Frishman et al., 1975; Miller et al., 1975; Gibson et al., 1976). Thus, it is not surprising that hypotension, congestive heart failure, and conduction disturbances are among the complications of therapy with propranolol (Stephen, 1966). It is for these reasons that the search continues for a pharmacological agent capable of betaadrenergic blockade with a more favourable therapeutic index, a more convenient dosage schedule, and with less depression of the myocardium.

Received for publication 30 December 1977
Nadolol, a beta-adrenergic receptor blocking agent, has been reported to be nearly four times as effective as propranolol in blocking isoprenalineinduced tachycardia in anaesthetised dogs and yet less depressant to the myocardium (Lee et al., 1975; Gibson et al., 1976). In humans, oral nadolol (10 to $80 \mathrm{mg}$ ) has been shown to decrease the heart rate response to isoprenaline for a number of hours with apparently very little effect on blood pressure (Vukovich et al., 1976).

Accordingly, this study was designed to compare the efficacy of nadolol with propranolol in patients with angina pectoris. Sequential measurements of exercise tolerance on a motor-driven treadmill, echocardiograms, phonocardiograms, and synchronised end-diastolic chest $x$-ray films were objective measurements in this study. 


\section{Subjects and methods}

Informed consent for this study was obtained from 14 men with ischaemic heart disease ${ }^{1}$. Criteria for inclusion were: (1) the presence of stable angina pectoris and absence of acute myocardial infarction during the preceding four months; (2) the presence of electrocardiographic evidence of myocardial ischaemia during treadmill exercise testing and/or arteriographic evidence of greater than 60 per cent obstruction of the lumen of at least two major coronary arteries; (3) the absence of congestive heart failure as judged by a cardiothoracic ratio of less than 52 per cent and by absence of pulmonary congestion on the chest $x$-ray, and, with two exceptions, the absence of a third heart sound; (4) a resting diastolic blood pressure less than $90 \mathrm{mmHg}$; (5) the absence of severe bradycardia, second or third degree atrioventricular block, or bronchial asthma; and (6) the absence of other cardiac or severe systemic disease.

All patients were Caucasian men, 9 had either electrocardiographic or serum enzyme changes as evidence of previous myocardial infarction, and none had a history suggesting peripheral vascular or cerebrovascular disease. No patient had had previous cardiac surgery (Table 1 ).

\section{EXPERIMENTAL DESIGN}

With the exception of glyceryl trinitrate, all drugs were discontinued before entry into the study. Patients were evaluated according to a randomised, double blind, crossover experimental design (Fig. 1). Placebo and drug therapy were given four times

${ }^{1}$ The study was approved by the Subcommittee on Human Studies (of the Minneapolis Veterans Administration Hospital) on 8 May 1974. daily; propranolol was given in four equal amounts, while nadolol was given twice daily with the additional tablets being placebos.

Glyceryl trinitrate was taken only for chest pain of sufficient severity to warrant its use. Each patient kept a diary of daily consumption of glyceryl trinitrate. The last two weeks of the placebo period I were used as a baseline of consumption.

Propranolol has a peak blood concentration 1 to $1 \frac{1}{2}$ hours after an oral dose, with a half-life of 2 to 3 hours (Paterson et al., 1970). Nadolol has a peak blood concentration of 3 hours after an oral dose, with a half-life of 17 hours (Vukovich et al., 1976). Because of this difference in time-concentration curves, we chose a time midway between the two peaks at which to cluster our testing (Fig. 2).

Phonocardiograms and external carotid pulse tracings were recorded on a Electronics for Medicine DR-8 multichannel photographic recorder using a ceramic microphone (Electronics for Medicine PSA-1 and 2) with a frequency response flat from 50 to $2000 \mathrm{~Hz}$ and a time constant of 1.2 seconds in the pulse position. The left ventricuiar ejection time (LVET), pre-ejection period (PEP), and total electromechanical systole $\left(\mathrm{QS}_{2}\right)$ were measured according to standard techniques (Weissler et al., 1969). Mean systolic time intervals were then corrected for heart rate (e.g. PEPc) using the linear regression equations of Weissler et al. (1972).

Echocardiograms were recorded according to the sequence shown in Fig. 1. A Smith-Kline Ekoline 20, Mark II Ultrasonoscope with a $2.25 \mathrm{mHz}$ transducer of 0.50 inch diameter and a repetition rate of 1000 pulses/s was used as the sensor. Echograms were recorded in time motion mode by means of a Honeywell 1856 strip chart recorder. Simultaneous echoes from the left ventricular pos-

Table 1 Clinical findings in 14 patients with angina pectoris

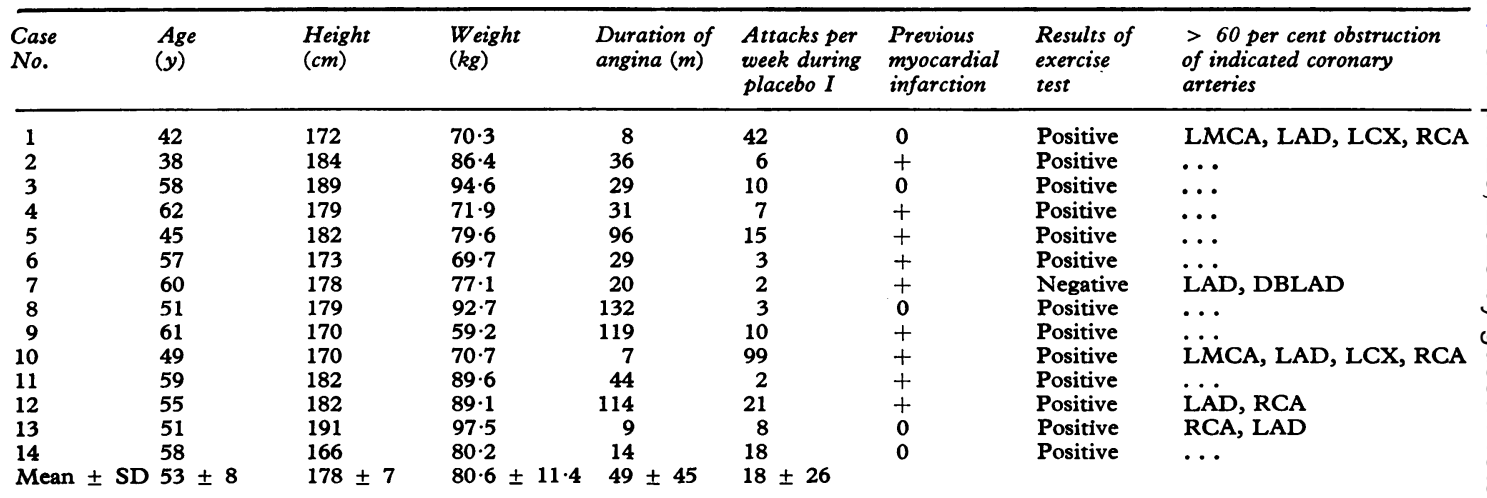

0, absent; +, present; . . ., no test performed; LMCA, left main coronary artery; LAD, left anterior descending coronary artery; LCX, left circumflex coronary artery; RCA, right coronary artery; DBLAD, diagonal branch of the LAD. 


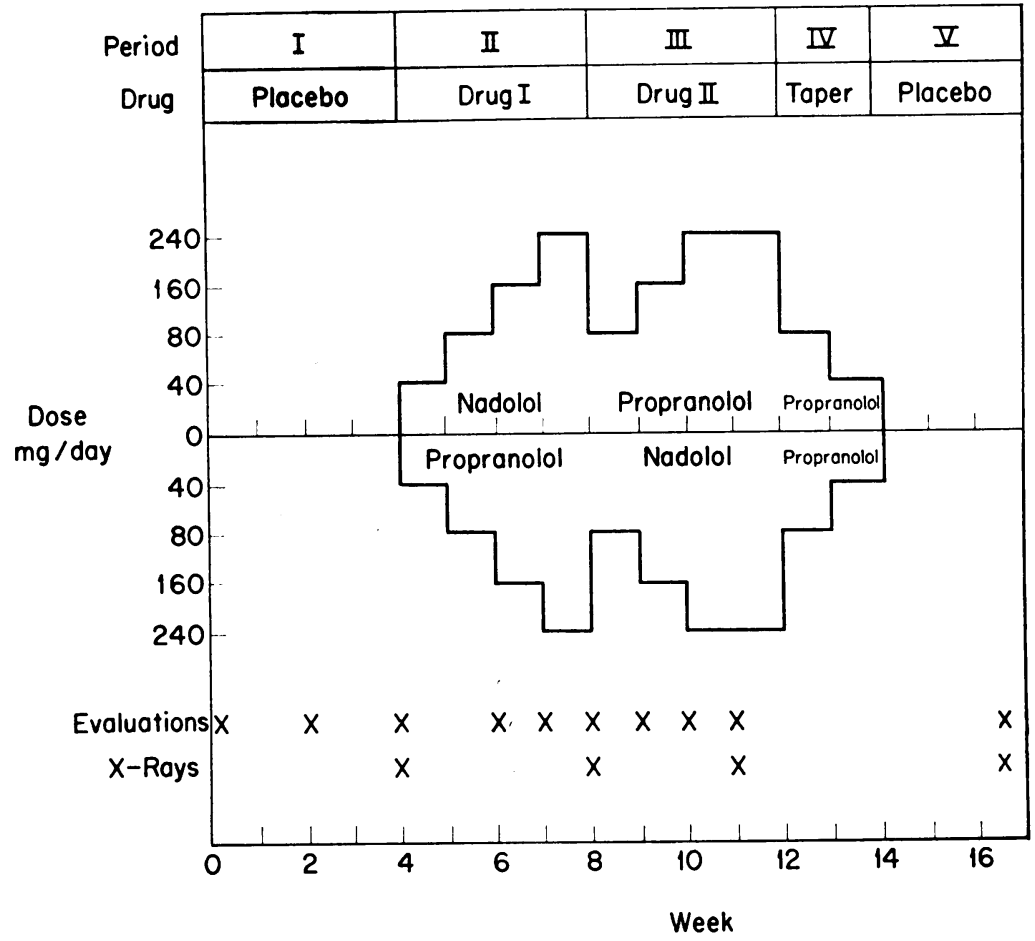

Fig. 1 The drug trial was divided into 5 periods; the first ( 3 or 4 weeks) was a placebo period; the second (4 weeks) was a randomised double-blind treatment period with nadolol or propranolol given in the following weekly sequence: 40, 80, 160 , and $240 \mathrm{mg}$ per day; the third (4 weeks) was a second treatment period on the alternate drug given in the following weekly sequence: 80,160, 240, and $240 \mathrm{mg}$ per day; the fourth ( 1 or 2 weeks) was a dose-tapering period with propranolol given in the following weekly sequence: 80 and $40 \mathrm{mg}$ per day; and the fifth (2 to 4 weeks) was a placebo period. Evaluations indicated by $X$ included an exercise test, phonocardiogram, and an echocardiogram. $X$-ray films indicated by $X$ refer to chest $\mathrm{x}$-rays electrocardiographically synchronised to end-diastole.

terior wall and interventricular septum were recorded. The T-scan method of Henry et al. (1973) was used. The end-diastolic diameter, the end-systolic diameter, the end-diastolic volume, and end-systolic volume were calculated according to standard techniques (Fortuin et al., 1971; Pombo et al., 1971; Feigenbaum et al., 1972). Mean velocity of posterior wall motion was measured as the slope of the wall movement from end-diastole to end-systole.

Multistage upright exercise testing was performed with the use of a motor-driven treadmill according to the procedure of Bruce and Blackmon (Bruce and Hornsten, 1969) (Fig. 1). Seven lead electrocardiograms were recorded at rest and a modified Blackburn lead system (Blackburn et al., 1967) combined with an inferior lead was used during exercise as previously reported (Hartman et al., 1976). The systolic blood pressure was determined from an external cuff and Korotkoff's sounds. The rate pressure product is the product of the heart rate and peak systolic blood pressure. Electrocardiographic evidence of ischaemia was defined as flat or downsloping ST segment depression of $1 \mathrm{~mm}$ or greater at $0.08 \mathrm{~s}$ after the J junction. Heart rate and blood pressure were measured during the last minute and the last 10 seconds of exercise. External work was calculated from the distance walked and the slope and speed of the treadmill, and expressed as kilogramme metres. Exercise was performed in the morning after 10 to 12 hours of fasting, and at least 6 hours of non-smoking. Routine medication during the study consisted only of glyceryl trinitrate and the placebo or the study drugs. No patient received digitalis, diuretics, or any other medication during 


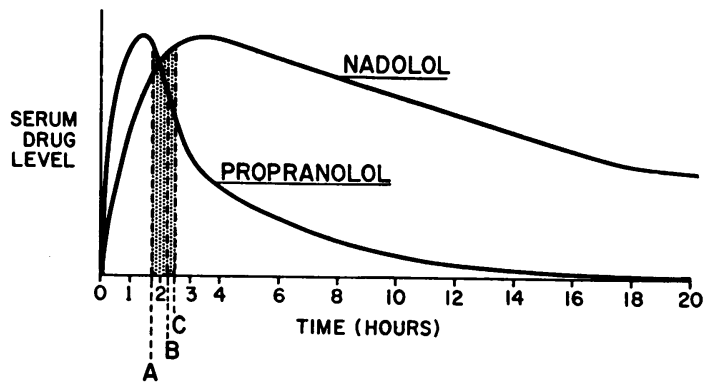

Fig. 2 Relation between performing phonocardiograms $(A)$, echocardiograms $(B)$, and exercise stress tests $(C)$, and expected serum levels of nadolol and propranolol.

the study. During testing, there was no change in the patients' smoking habits or weight (mean $80 \cdot 6 \pm$ $11.4 \mathrm{~kg}$ at entrance and $81.3 \pm 11.3 \mathrm{~kg}$ at termination of the study).

All patients exercised to symptom-tolerated maximum exercise consisting of either grade 2 chest pain or inability to continue because of dyspnoea and leg fatigue (Hartman et al., 1976). In one instance (case 1) the exercise test was discontinued because of the development of ventricular fibrillation requiring DC shock for cardioversion. Patients were instructed to grade chest pain in 5 categories ( 0 to 4 ) such that grade 2 chest pain would represent about 50 per cent of the patient's most severe pain or pain of sufficient severity that the patient would usually take a glyceryl trinitrate tablet. This was used as the endpoint for all exercise tests. Such a grading system has been used successfully by us (Hartman et al., 1976; Gobel et al., 1978), and by others (Smokler et al., 1973).

Change in ventricular volume was also determined from posterior-anterior and lateral chest $x$-rays synchronised to end-diastole (the onset of the $\mathbf{R}$ wave) (Becker et al., 1968). The transverse cardiac diameter, cardiothoracic ratio, and volume of the heart were calculated from these $x$-ray films. Cardiac volume was calculated by a modification of the method of Kahlstorf (1933) (Jonsell, 1939; Ungerleider and Gubner, 1942) (Fig. 2). Heart volume was calculated as the product of the long, the true short, and the anteroposterior diameters with correction for magnification (Fig. 3). Volume was expressed as millilitres per square metre body surface area $\left(\mathrm{ml} / \mathrm{m}^{2} \mathrm{BSA}\right)$. The results were then compared with mean values derived from 125 normal men in our laboratory ( $351.5 \pm 39.8 \mathrm{ml} / \mathrm{m}^{2}$ BSA).

Pulmonary function was evaluated in the first 8 patients from spirometry, total body plethysmography, and flow volumes loops. Measurements were obtained while patients were receiving $240 \mathrm{mg}$

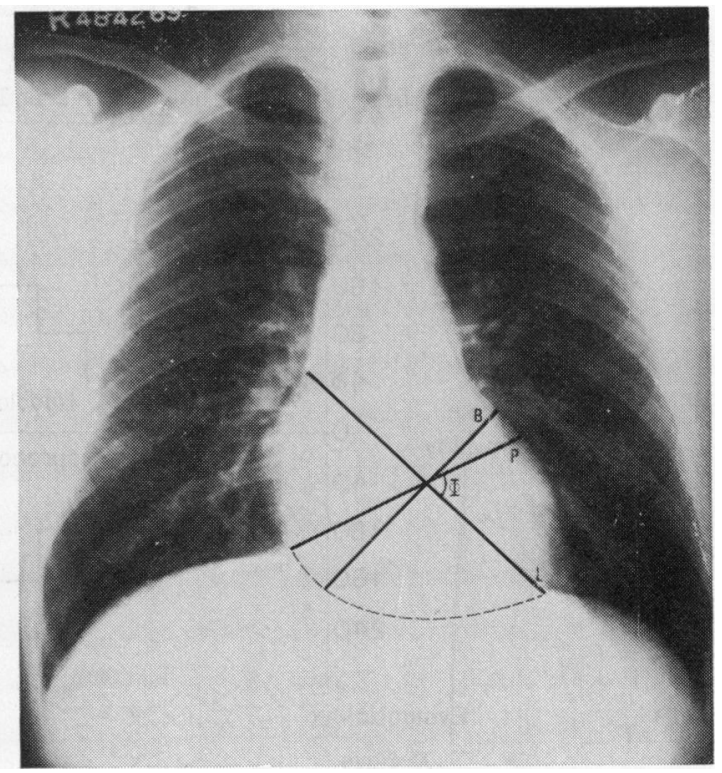

Fig. 3 Heart volume was determined from the posteroanterior and lateral $\mathrm{x}$-ray films by assuming that the heart is an ellipsoid. Three diameters at right angles were employed: (1) the long diameter of the ellipsoid $(L)$, which extends from the junction of the ascending aorta and the right atrium to the apex of the heart. An oblique diameter $(P)$ was drawn from the junction of the right heart border and diaphragm, through the midpoint of the longitudinal axis, to the left heart border; (2) the true short diameter $(B)$ of the ellipsoid was calculated from the long diameter, the oblique diameter, and the angle between them; and (3) the maximum anteroposterior diameter $(D)$ of the ellipsoid measured parallel to the intervertebral spaces on the lateral projection. $B$ is further defined as:

$$
B=\frac{\sin Q}{\sqrt{\frac{1}{p^{2}}-\frac{\operatorname{Cos}^{2} Q}{L 2}}}
$$

Cardiac volume $/ m^{2}=\frac{L \times B \times D \times F}{\text { body surface area }}$

$F$ is the product of $\pi / 6$ and the magnification factor.

of each drug and compared with measurements made during placebo. Forced expiratory volume in one second $\left(\mathrm{FEV}_{1}\right)$, forced expiratory volume in $3 \stackrel{\mathrm{O}}{\mathrm{N}}$ seconds $\left(\mathrm{FEV}_{3}\right)$, forced vital capacity (FVC), the $\mathrm{C}$ ratio of $\mathrm{FEV}, / \mathrm{FVC}(\mathrm{FEV}, \%)$, and maximum midexpiratory flow (MMEF) were calculated fromo Stead-Wells spirometry data (Comroe et al., 1962). Total lung capacity, thoracic gas volume, residual $\stackrel{+}{+}$ volume, airway resistance, and airway conductance $\frac{T}{T}$ (Gaw, $1 / \mathrm{AR}=\mathrm{Gaw}$ ) were calculated from total $\frac{\mathrm{O}}{\mathrm{D}}$ body plethysmography data (Comroe et al., 1962). $\stackrel{?}{?}$ Airway conductance was measured simultaneously $\stackrel{\circ}{\circ}$ 


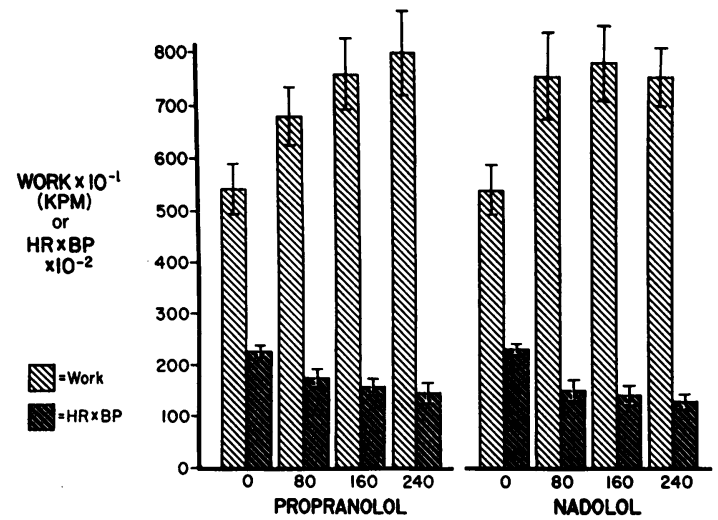

Fig. 4 Heart rate blood pressure product and external work performed ( \pm standard error of the mean) on placebo, 80, 160, and $240 \mathrm{mg}$ per day of either propranolol or nadolol.

with thoracic gas volume. Volume and flow taken from a 570 Wedge spirometer were recorded on an Electronics for Medicine oscilloscopic photographic recorder. Calculations were performed for the expiratory vital capacity, peak flow rates, and flow rates at 25,50 , and 75 per cent of the vital capacity manoeuvre (Bass, 1973).

Significance was determined by standard statistical methods (Snedecor and Cochran, 1967).

\section{Results}

All patients improved on medical treatment and there were no deaths or evidence of new myocardial infarction in any patient during the study.

Mean glyceryl trinitrate consumption decreased significantly from placebo during each dose of each drug (all $P<0.05$ ) (Table 2). There was no significant difference between the drugs at any dosage, or between dose levels for propranolol. However, $240 \mathrm{mg} /$ day of nadolol did produce a significant decrease in consumption of glyceryl trinitrate from $160 \mathrm{mg} /$ day $(P<0.05)$.

Although patients did not use glyceryl trinitrate
Table 2 Glyceryl trinitrate consumption (tablets per week, mean $\pm S D$ )

\begin{tabular}{|c|c|c|c|c|}
\hline & Control & 80 & 160 & 240 \\
\hline $\begin{array}{l}\text { Propranolol } \\
\text { Nadolol }\end{array}$ & $\begin{array}{l}15 \pm 22 \\
15 \pm 22\end{array}$ & $\begin{array}{l}6 \pm 8^{\star} \\
7 \pm 10^{\star}\end{array}$ & $\begin{array}{l}6 \pm 13 \dagger \\
6 \pm 10^{\star}\end{array}$ & $\begin{array}{l}8 \pm 16 \ddagger \\
5 \pm 8^{\star}\end{array}$ \\
\hline
\end{tabular}

* Change from control $\mathbf{P}<0.05$.

† Change from control $P<0.02$.

$\neq$ Change from control $P<0.01$.

for each episode of angina pectoris the number of episodes of chest pain a week decreased to a degree similar to that associated with consumption of glyceryl trinitrate. The number of attacks of chest pain decreased from a mean placebo value of $18 \pm$ 26 pains to 7 to 9 attacks per week with nadolol and 8 to 11 attacks per week with propranolol (all $\mathrm{P}<$ 0.05 ). At $240 \mathrm{mg}$ /day patients experienced slightly fewer chest pains per week with nadolol than with propranolol $(P<0.05)$. There was no significant difference at any other dose.

Between placebo periods I and V, there were no significant differences in any rate corrected systolic time interval. Though therapy with both propranolol and nadolol resulted in slight increases in mean values of $\mathrm{PEP}_{\mathrm{c}}, \mathrm{LVET}_{\mathrm{c}}$, and $\mathrm{QS}_{2 \mathrm{c}}$, significant differences were present only for $Q S_{2 c}(P<0.05)$ and, in one instance, the $\operatorname{PEP}_{c}(\mathbf{P}<0.02)$ (Table 3$)$. The degree of increase in $\mathrm{QS}_{2 \mathrm{c}}$ was not predictive of the drug dosage used. There were no significant differences in the ratio of PEP/LVET during treatment with either propranolol or nadolol at any dosage (Table 3).

In 7 patients simultaneous motion of the septum and posterior wall could be delineated by echocardiography and these patients were included for measurements of ventricular volume and posterior wall movement. There was no change in the internal diameter at end-diastole during therapy with either drug though a significant decrease in mean velocity of posterior wall motion was found during treatment with both propranolol and nadolol $(P<0.01)$.

There was no significant difference in heart rate, blood pressure, rate pressure product, duration of

Table 3 Systolic time intervals ( $m s$ ) $($ mean $\pm S D)$

\begin{tabular}{|c|c|c|c|c|c|c|c|c|c|c|c|c|c|}
\hline \multirow[t]{2}{*}{ Interval } & \multirow{2}{*}{\multicolumn{2}{|c|}{ Control }} & \multicolumn{6}{|c|}{ Propranolol } & \multicolumn{5}{|l|}{ Nadolol } \\
\hline & & & 80 & & 160 & & 240 & & 80 & & 160 & & 240 \\
\hline $\begin{array}{l}\text { PEPc }_{\text {c }} \\
\text { LVET }_{\text {c }} \\
\text { QS }_{\text {zc }} \\
\text { PEP/LVET }\end{array}$ & $\begin{array}{c}120 \pm 24 \\
419 \pm 18 \\
531 \pm 28 \\
0.31 \pm\end{array}$ & 0.09 & $\begin{array}{c}123 \pm 27 \\
421 \pm 27 \\
545 \pm 20 \\
0.32 \pm\end{array}$ & $0 \cdot 11$ & $\begin{array}{c}127 \pm 21^{\star} \\
420 \pm 19 \\
547 \pm 19 \star \\
0.32 \pm\end{array}$ & 0.08 & $\begin{array}{c}125 \pm 24 \\
423 \pm 21 \\
548 \pm 17 \star \\
0 \cdot 30 \pm\end{array}$ & $0 \cdot 11$ & $\begin{array}{c}129 \pm 23 \\
421 \pm 25 \\
550 \pm 22^{\star} \\
0.33 \pm\end{array}$ & 0.09 & $\begin{array}{c}120 \pm 23 \\
426 \pm 19 \\
546 \pm 14^{\star} \\
0 \cdot 30 \pm\end{array}$ & 0.09 & $\begin{array}{l}123 \pm 22 \\
426 \pm 25 \\
549 \pm 20^{\star} \\
0.31 \pm 0.09\end{array}$ \\
\hline
\end{tabular}

* Change from control $\mathbf{P}<0.05$. 
Table 4 Exercise tests

$($ mean $\pm S D)$

\begin{tabular}{|c|c|c|c|c|c|c|c|c|c|c|c|c|c|c|}
\hline & \multirow{2}{*}{\multicolumn{2}{|c|}{ Control }} & \multicolumn{6}{|c|}{ Propranolol } & \multicolumn{6}{|l|}{ Nadolol } \\
\hline & & & \multicolumn{2}{|l|}{80} & \multicolumn{2}{|l|}{160} & \multicolumn{2}{|l|}{240} & \multicolumn{2}{|l|}{80} & \multicolumn{2}{|l|}{160} & \multicolumn{2}{|l|}{240} \\
\hline \multicolumn{15}{|l|}{ Heart rate } \\
\hline Rest & $71 \pm$ & 9 & $60 \pm$ & $12^{\star}$ & $58 \pm$ & $6^{\star}$ & $57 \pm$ & $6 *$ & $55 \pm$ & $7 \star$ & $53 \pm$ & $5^{\star}$ & $54 \pm$ & $6^{\star}$ \\
\hline 2 minutes of exercise & $112 \pm$ & 9 & $93 \pm$ & $12^{\star}$ & $85 \pm$ & $7^{\star}$ & $85 \pm$ & $6 *$ & $83 \pm$ & $6^{\star}$ & $81 \pm$ & $7^{\star}$ & $78 \pm$ & $6 \star$ \\
\hline STME & $137 \pm$ & 18 & $117 \pm$ & $19 \star$ & $110 \pm$ & $12^{\star}$ & $107 \pm$ & $12^{\star}$ & $104 \pm$ & $13 \star$ & $99 \pm$ & $14^{\star}$ & $95 \pm$ & $12^{\star}$ \\
\hline \multicolumn{15}{|l|}{ Blood pressure (systolic) } \\
\hline Rest & $133 \pm$ & 17 & $125 \pm$ & $18^{\star}$ & $130 \pm$ & 21 & $123 \pm$ & 23 & $124 \pm$ & $17^{\star}$ & $124 \pm$ & $18^{\star}$ & $120 \pm$ & $22^{\star}$ \\
\hline 2 minutes of exercise & $146 \pm$ & 21 & $132 \pm$ & $19^{\star}$ & $131 \pm$ & $22 \star$ & $129 \pm$ & $21^{\star}$ & $124 \pm$ & $11^{\star}$ & $128 \pm$ & $16^{\star}$ & $124 \pm$ & $16^{\star}$ \\
\hline STME & $163 \pm$ & 17 & $147 \pm$ & $16^{\star}$ & $145 \pm$ & $22^{\star}$ & $145 \pm$ & $21^{\star}$ & $141 \pm$ & $20 \star$ & $140 \pm$ & $14^{\star}$ & $141 \pm$ & $18 *$ \\
\hline \multicolumn{15}{|l|}{$H R \times B P \times 10^{-2}$} \\
\hline STME (RPP) & $226 \pm$ & 49 & $172 \pm$ & $32^{\star}$ & $158 \pm$ & $27^{\star}$ & $155 \pm$ & $32^{\star}$ & $148 \pm$ & $34^{\star}$ & $140 \pm$ & $27^{\star}$ & $134 \pm$ & $26^{\star}$ \\
\hline Duration of exercise & $289 \pm$ & 74 & $344 \pm$ & 79* & $369 \pm$ & $77 \star$ & $374 \pm$ & $83^{\star}$ & $365 \pm$ & $90^{\star}$ & $374 \pm$ & $65^{\star}$ & $371 \pm$ & $64^{\star}$ \\
\hline Total work performed & $5401 \pm$ & 2058 & $6846 \pm$ & $2231^{\star}$ & $7764 \pm$ & $2443 \star$ & $7985 \pm$ & $=2498^{\star}$ & $7538 \pm$ & $3107^{\star}$ & $7721 \pm$ & $2397^{\star}$ & $7539 \pm$ & $2206^{\star}$ \\
\hline
\end{tabular}

* Change from control $P<0.05$. STME, symptom tolerated maximal exercise; HR, heart rate; RPP, rate pressure product.

exercise, or external work performed between the two exercise tests performed in the first placebo period. No significant changes in heart rate, blood pressure, or rate pressure product at rest, at 2 minutes of exercise, 30 to 60 seconds before stopping, and at symptom-tolerated maximal exercise were noted between placebo periods I and $\mathrm{V}$.

The effects of propranolol and nadolol on exercise performance are indicated in Table 4 . Heart rate significantly decreased from control with both drugs at rest $(P<0.001)$, at 2 minutes of exercise $(P<$ 0.001 ), and at symptom-tolerated maximal exercise $(\mathbf{P}<0.001)$ at all dosage levels. The decrease in heart rate from control at 2 minutes and symptomtolerated maximal exercise was greater during treatment with nadolol than with propranolol at each dosage level. The blood pressure decreased from control values during treatment with nadolol at rest $(P<0.001)$ at all dosage levels. During treatment with propranolol, blood pressure was decreased from control values at 2 minutes of exercise $(P<0.02)$ and at symptom-tolerated maximal exercise $(\mathbf{P}<$ $0.02)$ at each dosage level.

At $80 \mathrm{mg}$ a day of either drug, mean duration of exercise increased significantly by 55 seconds with propranolol $(P<0.01)$ and by 76 seconds with nadolol $(P<0.01)$, but the difference between the drugs was not significant. At this dosage, external work increased significantly from control values for both drugs (propranolol, $\mathbf{P}<0.02$; nadolol, $\mathbf{P}<$ 0.001 ) but the difference between the drugs was not significant. Improvement in work performance was associated with a significant reduction in the rate pressure product at symptom-tolerated maximal exercise which was greater during treatment with nadolol ( $34 \%$ versus $24 \%$ decrease, $P<0.02)$. Thus, at $80 \mathrm{mg}$ daily there was a similar increase in exercise duration and work performance, but nadolol resulted in a significantly greater decrease in rate pressure product at symptom-tolerated maximal exercise $(P<0.02)$.

Similar changes were noted at $160 \mathrm{mg}$ per day of each drug. There was a further increase in duration of exercise and in external workload from control values but the difference from $80 \mathrm{mg}$ daily was not significant. There was a 30 per cent decrease in rate pressure product at symptom-tolerated maximal exercise during propranolol $(P<0.001)$ and a 38 per cent decrease in rate pressure product with nadolol $(P<0.001)$. During nadolol therapy there was a significantly lower heart rate and rate pressure product at rest $(P<0.01)$, at 2 minutes of exercise $(P<0.05), 30$ to 60 seconds before symptomtolerated maximal exercise $(P<0.01)$, and at symptom-tolerated maximal exercise $(P<0.02)$ when compared with values obtained during propranolol therapy.

When the dosage of both drugs was increased from 160 to $240 \mathrm{mg}$ per day, the duration of exercise and external work performed increased with propranolol but not with nadolol, but there was not a significant difference between the drugs. At this dosage the decrease in heart rate and rate pressure product at symptom-tolerated maximal exercise from control was slightly greater during treatment with nadolol than with propranolol (heart rate, $P<0.001$; rate pressure product, $P<0.05$ ). At 2 minutes of exercise the heart rate and rate pressure product also were less during nadolol than during propranolol (both $\mathrm{P}<0.001$ ). Propranolol, $240 \mathrm{mg}$ daily, was the lowest dosage necessary for 7 patients to achieve their maximal duration of exercise, while 4 achieved maximum at $160 \mathrm{mg}$ and 3 at $80 \mathrm{mg}$ daily. In 4 patients maximum duration of exercise was achieved by nadolol $240 \mathrm{mg}$ per day while 7 patients achieved their maximum duration of exercise at $160 \mathrm{mg}$ per day and 3 at $80 \mathrm{mg}$ per day. In fact, increasing the 
dose of nadolol from 160 to $240 \mathrm{mg}$ per day resulted in a decrease in duration of exercise in 9 patients (mean decrease, $27 \pm 21$ seconds). However, in only 2 patients did increasing the dose of propranolol from 160 to $240 \mathrm{mg}$ per day result in a decrease in exercise time ( $65 \pm 63$ seconds).

When exercise tests were performed following an identical morning dose of each drug $(40 \mathrm{mg}$, which occurred at $160 \mathrm{mg}$ per day of propranolol, and $80 \mathrm{mg}$ per day of nadolol), there were equivalent increases in duration of exercise and equivalent decreases in heart rate at rest and at 2 minutes of exercise. Nadolol decreased rate pressure product more than propranolol at 2 minutes of exercise $(\mathbf{P}<0.05)$. The heart rate was significantly lower with nadolol than propranolol at symptom-tolerated maximal exercise and at 30 to 60 seconds before symptom-tolerated maximal exercise. Though nadolol and propranolol decreased exercise blood pressure from control values there was no difference between the drugs at equivalent morning doses.

Significant changes in the radiograph cardiac silhouette were noted on $240 \mathrm{mg}$ per day of both drugs. There was a significant increase in the mean transverse diameter of the heart during propranolol therapy from control value of $13.9 \pm 1.2 \mathrm{~cm}$ to $14.5 \pm 1.0 \mathrm{~cm}(P<0.01)$. An additional significant mean increase of $0.6 \mathrm{~cm}(\mathrm{P}<0.02)$ occurred during nadolol treatment to $15.1 \pm 1.0 \mathrm{~cm}(P<0.001)$. The mean transverse diameter and cardiothoracic ratio were greater with nadolol than propranolol $(P<0.02$, and $P<0.001)$. Cardiac volume measured from the end-diastolic chest $x$-rays also increased from a mean control value of $406 \pm$ $80 \mathrm{ml} / \mathrm{m}^{2} / \mathrm{BSA}$ to $456 \pm 78$ on propranolol $(\mathrm{P}<$ 0.001 ) and to $473 \pm 73 \mathrm{ml} / \mathrm{m}^{2} / \mathrm{BSA}$ during nadolol $(\mathrm{P}<0.01)$. Though the mean volume was larger with nadolol than propranolol, the difference was not significant. In one instance (case 11) there was both an increase in heart size and evidence of increased upper pulmonary blood volume. This patient was noted to have the greatest change in transverse diameter and heart volume as well. No other radiographic signs of congestive heart failure were noted on any patient. In case 12, elevation of the left diaphragm prevented accurate delineation of the left heart border while technical difficulties precluded end-diastolic chest $x$-ray films in cases 1 and 13 while receiving nadolol and these 3 patients were therefore excluded from analysis.

There were no significant differences in pulmonary function tests between the two placebo periods. There was no significant change from control values in airway resistance, airway conductance (Gaw), thoracic gas volume (TGV), residual volume (RV), total lung capacity (TLC), RV/TLC per cent, Gaw/TGV, or FEV $1 / F V C$ during propranolol or nadolol therapy (Table 5). There were small decreases in FVC $(P<0.02)$, FEV $1(P<0.01)$, $\mathrm{FEV}_{3}(\mathrm{P}<0.001)$, and maximum mid-expiratory flow $(P<0.02)$ during drug treatment, but they only assumed significance with nadolol. Clinically small but statistically significant (all $P<0.05$ ) reductions were noted in peak flow rates at 25 per cent and 50 per cent of FVC during both propranolol and nadolol therapy.

\section{Discussion}

Results from this study indicate that both propranolol and nadolol effected significant symptomatic improvement whether judged by glyceryl trinitrate consumption or episodes of angina pectoris. This was not likely to be the result of physical conditioning as the placebo periods $I$ and $V$ were not significantly different. In no patient was it necessary

Table 5 Pulmonary function tests in first 8 patients

\begin{tabular}{|c|c|c|c|c|c|}
\hline Pulmonary test $\dagger$ & Control & \multicolumn{2}{|c|}{$\begin{array}{l}\text { Propranolol } \\
240 \mathrm{mg} / \text { day }\end{array}$} & \multicolumn{2}{|c|}{$\begin{array}{l}\text { Nadolol } \\
240 \mathrm{mg} / \text { day }\end{array}$} \\
\hline 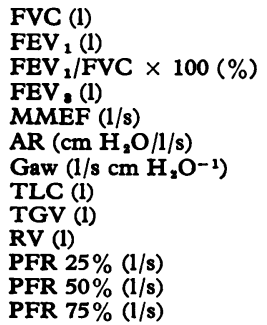 & $\begin{array}{cl}4.64 & \pm 1.1 \\
3.06 & \pm 0.90 \\
65.9 & \pm 8.4 \\
4.03 & \pm 1.0 \\
2.57 & \pm 1.4 \\
1.69 & \pm 1.2 \\
0.864 & \pm 0.62 \\
7.76 & \pm 1.4 \\
4.35 & \pm 0.71 \\
2.95 & \pm 0.65 \\
6.54 & \pm 2.5 \\
3.06 & \pm 1.7 \\
0.82 & \pm 0.58\end{array}$ & $\begin{array}{l}4.52 \\
2.93 \\
64 \cdot 2 \\
3.87 \\
2.46 \\
1.96 \\
0.633 \\
7 \cdot 86 \\
4 \cdot 49 \\
3 \cdot 18 \\
5.53 \\
2.61 \\
0.72\end{array}$ & 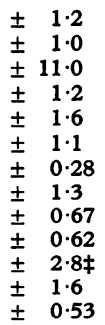 & $\begin{array}{c}4.49 \\
2.94 \\
65 \cdot 0 \\
3 \cdot 87 \\
2 \cdot 37 \\
1.62 \\
0.757 \\
7.69 \\
4.36 \\
2 \cdot 89 \\
5 \cdot 74 \\
2.55 \\
0.67\end{array}$ & $\begin{array}{l} \pm 1 \cdot 2^{\star} \\
\pm 0.88 \ddagger \\
\pm 8 \cdot 4 \\
\pm 1 \cdot 0 \$ \\
\pm 1 \cdot 4 \\
\pm 0.94 \\
\pm 0.32 \\
\pm 1.4 \\
\pm 0.93 \\
\pm 0.69 \\
\pm 2 \cdot 23^{\star} \\
\pm 1 \cdot 4^{\star} \\
\pm 0.43\end{array}$ \\
\hline
\end{tabular}

+ See text for abbrevations.

$\star \mathbf{P}<0.02$.

$¥ \mathbf{P}<0.01$.

S $\mathbf{P}<0.001$. 
to discontinue either drug because of unwanted effects. Patients complained of fatigue with similar frequency for both drugs, but diarrhoea and lightheadedness appeared more commonly with propranolol than with nadolol.

The negative chronotropic effect of both drugs, though present at rest, was best evaluated during exercise. Though there was a significant decrease in the mean resting heart rate with both drugs at each dosage level, in some individuals this change was small, and was magnified during exercise. Since most patients were able to exercise for at least 2 minutes, one could evaluate for drug effect at that time. Maximum drug effect was apparent when the heart rate at 2 minutes of exercise was suppressed by 25 to 30 per cent. At 2 minutes of exercise both nadolol and propranolol significantly decreased heart rate, blood pressure, and rate pressure product at all dosage levels.

Nadolol was more effective than propranolol in slowing the heart rate at rest, during exercise, and at symptom-tolerated maximal exercise. This was true at each dosage level, at an equivalent daily dose, and at an equivalent dose the morning of the study. Ten hours elapsed between the evening and morning dose, however, which might favour a higher blood level of nadolol than propranolol since nadolol has been shown to have a longer half-life than propranolol (Vukovich et al., 1976) (Fig. 3). These results suggest that nadolol is more potent than propranolol.

The rate pressure product decreased at symptomtolerated maximal exercise during treatment with both propranolol and nadolol. Since a change in rate pressure product is usually a good predictor of a change in myocardial oxygen consumption this might imply a decrease in myocardial oxygen consumption at symptom-tolerated maximal exercise. However, an increase in ventricular volume, as demonstrated from end-diastolic chest $x$-ray films, may in part have led to a similar level of myocardial oxygen consumption at a lower rate pressure product at symptom-tolerated maximal exercise during treatment with propranolol and nadolol (Gobel et al., 1978). The increase in volume may have resulted from a decrease in contractility with a resultant increase in fibre length (Gobel, 1976). This in turn would increase $\mathrm{MVO}_{2}$ at the same rate pressure product and result in a lower rate pressure product at the same $\mathrm{MVO}_{2}$ (Gobel et al., 1978). The fact that there was no improvement in exercise tolerance from nadolol 160 to nadolol 240 despite further suppression of rate pressure product at symptom-tolerated maximal exercise indicates that an increase in ventricular volume may have balanced the beneficial effect on heart rate and blood pressure and suggests that in such patients the dosage is best left at $160 \mathrm{mg}$ daily. Perhaps an increase in volume was more readily appreciated from the chest $x$-ray than the echocardiogram because more dimensions were available for calculation. In addition, since the entire cardiac silhouette was used, small increases in volume in each chamber may have been additive. Though the increase in heart size was significant and might be helpful in assessing the optimal dose of either beta-adrenergic blocking drug, careful mensuration and timing of the $x$-ray exposure is necessary since these small changes may not be apparent from casual observation.

Although previous data have indicated that airway resistance may increase after propranolol given intravenously to both normal subjects and patients with chronic obstructive lung disease (MacDonald et al., 1967; Nordstrom et al., 1975), airway resistance did not change significantly from control under the conditions of this study. Thus, exercise results were not influenced by the effect of either drug on airway resistance. These results are consistent with previous studies by Nordstrom et al. (1975) where a small but statistically significant increase in airway resistance and decrease in airway conductance were associated with no change in duration of exercise in either patients with chronic obstructive lung disease or in patients with chronic obstructive lung disease and heart disease. The reduction in FVC, $\mathrm{FEV}_{1}, \mathrm{FEV}_{3}$, and peak flow rates with nadolol may be consistent with an encroachment on small airways secondary to a mild, but clinically undetectable increase in pulmonary venous pressure. Though statistically significant, these changes are small and are not likely to be clinically significant.

Echocardiographic measurements of left ventricular internal diameters in patients with ischaemic heart disease may not be representative of the entire left ventricle, especially when asynergy is present. This sampling problem may lead to inaccuracies in estimation of ventricular volume and motion in such patients (Popp et al., 1973; Ratshin et al., 1973; Johnson, 1976; Teichholz et al., 1976). Previously reported results by Frishman et al. (1975) showed significant changes in end-diastolic volume, ejection fraction, and posterior wall velocity in patients who were given increasing amounts of propranolol. In that study, changes in end-diastolic and end-systolic dimension were not significant. Differences were only significant when these values were cubed to determine volume. With the exception of the reduction in left ventricular posterior wall velocity we were unable to show similar changes in our study. This may be because of the higher incidence of electrocardiographically proven previous myocardial infarction (4 of 7 patients) in our group of 
patients and hence, more segmental ventricular wall abnormalities (Popp et al., 1973; Johnson, 1976; Teichholz et al., 1976). In addition, an all-male population with large thoraces prevented us from obtaining echocardiograms suitable for measurements in all patients (Feigenbaum and Chang, 1972). Thus, the echocardiogram was not a useful way of evaluating drug effects in the patients with ischaemic heart disease in this study.

Propranolol and nadolol were supplied by the Squibb Institute for medical research.

\section{References}

Alderman, E. L., Davies, R. O., Crowley, J. J., Lopes, M. G., Brooker, J. Z., Friedman, J. P., Graham, A. F., Matlof, H. J., and Harrison, D. C. (1975). Dose response effectiveness of propranolol for the treatment of angina pectoris. Circulation, 51, 964-975.

Bass, H. (1973). The flow volume loop: normal standards and abnormalities in chronic obstructive pulmonary disease. Chest, 63, 171-176.

Becker, H. C., Meyers, P. H., Nice, C. M., Jr., and Goldstein, M. (1968). A new cardiac X-ray synchronizer system with cathode-ray tube display. Bulletin of the Tulane University Medical Faculty, 27, 147-153.

Blackburn, H., Taylor, H. L., Okamoto, N., Rautharju, P., Mitchell, P. A., and Kerkhof, A. C. (1967). Standardization of the exercise electrocardiogram. A systematic comparison of chest lead configuration employed for monitoring during exercise. In Physical Activity and the Heart: Proceedings of a Symposium (Helsinki, Finland), pp. 101-133. Ed. by M. J. Karvonen and A. J. Barry. Thomas, Springfield, Illinois.

Bruce, R. A., and Hornsten, T. R. (1969). Exercise stress testing in the evaluation of patients with ischemic heart disease. Progress in Cardiovascular Diseases, 11, 371-390.

Comroe, J. H., Jr., Forster, R. E., II, Dubois, A. B., Briscoe, W. A., and Carlsen, E. (1962). The Lung: Clinical Physiology and Pulmonary Function Tests, pp. 7-25; 178-184. Year Book Medical Publishers, Chicago, Illinois.

Feigenbaum, H., and Chang, S. (1972). Echocardiography, pp. 41 and 211. Lea and Febiger, Philadelphia.

Feigenbaum, H., Popp, R. L., Wolfe, S. B., Troy, B. L., Pombo, J. F., Haine, C. L., and Dodge, H. T. (1972). Ultrasound measurements of the left ventricle: a correlative study with angiocardiography. Archives of Internal Medicine, 129, 461-467.

Fortuin, N. J., Hood, W. P., Jr., Sherman, M. E., and Craige, E. (1971). Determination of left ventricular volumes by ultrasound. Circulation, 44, 575-584.

Frankl, W. S., Smith, W. K., Rose, F. D., MacMillan, R., Gomez, R., and Harkins, M. (1974). Experience with a multicenter study in the evaluation of propranolol as an effective antianginal agent. Fournal of Clinical Pharmacology, 14, 13-16.

Frishman, W., Smithen, C., Befler, B., Kligfield, P., and Killip, T. (1975). Noninvasive assessment of clinical response to oral propranolol therapy. American fournal of Cardiology, 35, 635-644.

Gibson, J. K., Gelband, H., and Bassett, A. L. (1976). Possible basis of antiarrhythmic action of a new betaadrenergic blocking compound SQ-11,725 (nadolol) (abstract). American fournal of Cardiology, 37, 138.

Gobel, F. L. (1976). Role and rationale of the use of pro- pranolol in the treatment of patients with angina pectoris. Minnesota Medicine, 59, 601-607.

Gobel, F. L., Nordstrom, L. A., Nelson, R. R., Jorgensen, C. R., and Wang, Y. (1978). The rate-pressure product as an index of myocardial oxygen consumption in patients with angina. Circulation, 57, 549-556.

Hartman, K. E., Nordstrom, L. A., and Gobel, F. L. (1976). Effect of placebo on exercise response and nitroglycerin consumption. Minnesota Medicine, 59, 839-843.

Henry, W. L., Clark, C. E., and Epstein, S. E. (1973). Asymmetric septal hypertrophy. Circulation, 47, 225-233.

Johnson, M. L. (1976). Echocardiographic evaluation of left ventricular size and function and its application in coronary artery disease. Advances in Cardiology, 17, 105-122.

Jonsell, S. (1939). A method for the determination of the heart size by teleroentgenography (a heart volume index). Acta Radiologica, 20, 325-340.

Kahlstorf, A. (1933). Uber Korrelationen der linearen Herzmasse und des Herzvolumens. Klinische Wochenschrifte, 12, 262-265.

Lee, R. J., Evans, D. B. Baky, S. H., and Laffan, R. J. (1975). Pharmacology of nadolol (SQ-11,725), a beta adrenergic antagonist lacking direct myocardial depression. European Fournal of Pharmacology, 33, 371-382.

MacDonald, A. G., Ingram, C. G., and McNeill, R. S. (1967). The effect of propranolol on airway resistance. British Fournal of Anaesthesia, 39, 919-926.

Miller, R. R., Olson, H. G., Pratt, C. M., Amsterdam, E. A., and Mason, D. T. (1975). Efficacy of beta adrenergic blockade in coronary heart disease: propranolol in angina pectoris. Clinical Pharmacology and Therapeutics, 18, 588-605.

Nordstrom, L. A., MacDonald, F., and Gobel, F. L. (1975). Effect of propranolol on respiratory function and exercise tolerance in patients with chronic obstructive lung disease. Chest, 67, 287-292.

Paterson, J. W., Conolly, M. E., and Dollery, C. T. (1970). The pharmacodynamics and metabolism of propranolol in man. European fournal of Clinical Pharmacology, 2, 127-133.

Pombo, J. F., Troy, B. L., and Russell, R. O. (1971). Left ventricular volumes and ejection fraction by echocardiography. Circulation, 43, 480-490.

Popp, R. L., Alderman, E. L., Brown, O. R., and Harrison, D. C. (1973). Sources of error in calculation of left ventricular volumes by echography (abstract). American fournal of Cardiology, 31, 152.

Ratshin, R. A., Boyd, C. N., Jr., Rackley, C. E., Moraski, R. E., and Russell, R. O., Jr. (1973). Quantitative echocardiography: correlations with ventricular volumes by angiocardiography in patients with coronary artery disease with and without wall motion abnormalities (abstract). Circulation, 47 and 48, Suppl. IV, 48.

Smokler, P. E., MacAlpin, R. N., Alvaro, A., and Kattus, A. A. (1973). Reproducibility of a multi-stage near maximal treadmill test for exercise tolerance in angina pectoris. Circulation, 48, 346-351.

Snedecor, G. W., and Cochran, W. G. (1967). Statistical Methods Applied to Experiments in Agriculture and Biology, 6th ed. Iowa State University Press, Ames, Iowa.

Stephen, S. A. (1966). Unwanted effects of propranolol. American fournal of Cardiology, 18, 463-468.

Teichholz, L. E., Kreulen, T. A., Herman, M. V., and Gorlin, R. (1976). Problems in echocardiographic volume determinations: echocardiographic-angiographic correlations in the presence and absence of asynergy. American fournal of Cardiology, 37, 7-11.

Ungerleider, H. E., and Gubner, R. (1942). Evaluation of heart size measurements. American Heart fournal, 24, 494-510.

Vukovich, R., Dreyfuss, J., Brannick, L. J., Herrera, J., and 
Willard, D. (1976). Pharmacologic and metabolic studies with a new beta-adrenergic blocking agent, nadolol (abstract). Clinical Research, 24, 513.

Weissler, A. M., Harris, W. S., and Schoenfeld, C. D. (1969). Bedside technics for evaluation of left ventricular function in man. American fournal of Cardiology, 23, 577-583.

Weissler, A. M., Lewis, R. P., and Leighton, R. F. (1972). The systolic time intervals as a measure of left ventricular performance in man. In Progress in Cardiology, p. 155. Ed. by P. N. Yu and J. F. Goodwin. Lea and Febiger, Philadelphia.

Requests for reprints to Dr Fredarick L. Gobel, 2545 Chicago Avenue South, Minneapolis, Minnesota 55404, USA. 